\title{
Durability of Mortar Made with Fine Glass Powdered Particles
}

\author{
Rosemary Bom Conselho Sales, ${ }^{1}$ Fernando Augusto Sales, ${ }^{2}$ Enio Pazini Figueiredo, ${ }^{3}$ \\ White José dos Santos, ${ }^{4}$ Nelcy Della Santina Mohallem, ${ }^{5}$ and Maria Teresa Paulino Aguilar ${ }^{4}$ \\ ${ }^{1}$ Departamento de Planejamento e Configuração, Universidade do Estado de Minas Gerais, \\ Av. Presidente Antônio Carlos, 7545 Bairro São Luiz, 31270-010 Belo Horizonte, MG, Brazil \\ ${ }^{2}$ Centro Federal de Educação Tecnológica de Minas Gerais, Departamento de Engenharia Mecânica, \\ Av. Amazonas, 7675 Nova Gameleira, 30510-000 Belo Horizonte, MG, Brazil \\ ${ }^{3}$ Departamento de Engenharia de Materiais, Universidade Federal de Goiás, \\ Av. Esperança, s/n Setor Itatiaia, 74690-900 Goiânia, GO, Brazil \\ ${ }^{4}$ Departamento de Engenharia de Materiais e Construção Civil, Universidade Federal de Minas Gerais, \\ Av. Presidente Antônio Carlos, 6627 Pampulha, 31270-901 Belo Horizonte, MG, Brazil \\ ${ }^{5}$ Departamento de Química, Universidade Federal de Minas Gerais, Av. Presidente Antônio Carlos, \\ 6627 Pampulha, 31270-901 Belo Horizonte, MG, Brazil
}

Correspondence should be addressed to Rosemary Bom Conselho Sales; rosemary.sales@uemg.br

Received 13 February 2017; Revised 12 April 2017; Accepted 20 April 2017; Published 31 July 2017

Academic Editor: Xiao-Yong Wang

Copyright (C) 2017 Rosemary Bom Conselho Sales et al. This is an open access article distributed under the Creative Commons Attribution License, which permits unrestricted use, distribution, and reproduction in any medium, provided the original work is properly cited.

\begin{abstract}
Different studies investigate the use of waste glass in Portland cement compounds, either as aggregates or as supplementary cementitious materials. Nevertheless, it seems that there is no consensus about the influence of particle color and size on the behavior of the compounds. This study addresses the influence of cement replacement by 10 and $20 \%$ of the colorless and amber soda-lime glass particles sized around $9.5 \mu \mathrm{m}$ on the performance of Portland cement mortars. Results revealed that the partial replacement of cement could contribute to the production of durable mortars in relation to the inhibition of the alkali-aggregate reaction. This effect was more marked with $20 \%$ replacement using amber glass. Samples containing glass microparticles were more resistant to corrosion, in particular those made of colorless glass. The use of colorless and amber glass microparticles promoted a reduction in wear resistance.
\end{abstract}

\section{Introduction}

Portland cement production is associated with high-energy consumption, greenhouse gas emissions, and the consumption of natural resources $[1,2]$. The use of wastes as supplementary cementitious materials is an alternative to mitigate such negative impacts. Depending on particle size, silica content, and the degree of crystallinity, these wastes can be used as cements, pozzolanic admixture, or filler [3-5]. The most common wastes used in blended cements are blastfurnace slag, fly ash, silica fume, rice husk ash, and sugarcane bagasse ash [6-10]. Published results report that the use of glass particles for the partial replacement of aggregates or cement can result in beneficial or deleterious effects on the performance of cementitious compounds materials [11-17].
Waste glass is a noncrystalline ceramic material with high silica content and is inert and nonbiodegradable. These wastes in the form of cullets present high recovery and recycling rates [2]. However, in Brazil, waste glass in the form of powders constitutes an environmental liability because its recycling is not economically viable [18].

Studies on the incorporation of waste glass in cementitious materials began with its use as an aggregate and have extended to the present time $[15,19]$. According to some authors $[11,12,17,20]$, its use as aggregate is limited by the possibility of occurrence of the alkali-silica reaction. Moreover, there is the possibility of the formation of a weak transition zone, in the case of coarse aggregates, and low workability of the resulting compounds [13-15]. Idir et al. [21] consider that, depending on the particle size and color of the 
glass, such a reaction could be inhibited by the use of waste glass.

A number of published results report the existence of a critical size that would enable the pozzolanic reaction without the subsequent formation of an expansive gel as a result of the alkali-silica reaction [12, 13, 21-24]. However, there is no consensus about the influence of particle size and color on the behavior of the compounds.

According to Thomas [4] and Idir et al. [12], glass particles below $140 \mu \mathrm{m}$ could exhibit significant pozzolanic activity. For Khmiri et al. [17], Shao et al. [23], and Shi et al. [24], only ground waste glass below 38 or $45 \mu \mathrm{m}$ or even a few tenths of a micrometer could present pozzolanic activity. On the other hand, the pozzolanic activity of powdered glass can be optimized by curing at above ambient temperatures [19]. There is no consensus on the influence of glass color on the performance of compounds manufactured with waste glass in the replacement of aggregates. Du and Tan [11], Dhir et al. [20], and Topcu et al. [25] suggest that colorless glass has higher reactivity with alkalis than green and amber glasses, whereas others show that colorless glasses promote smaller expansions. A recent research work [11] using glass particles in partial and total replacement of sand reveals that, in comparison with green glass, amber glass causes less expansion due to the alkali-silica reaction. This is due to the pozzolanic reaction and the presence of internal cracks in the larger green glass particles. For different authors, glass particles of micron-order dimensions are effective in reducing the expansion of the alkali-silica reaction in the same manner as the effects of fly ash and slag [4, 18, $21,26,27]$. It has also been reported that color does not influence the alkali-aggregate reaction and that green glass has better pozzolanicity than amber glass. Mirzahosseini and Riding [28] reveal that green glass may present higher pozzolanic reactivity than colorless glass depending on the curing temperature. Dyer and Dhir [29] showed that mortar containing colorless and green glasses result in compressive strengths somewhat higher than that of the mortar without glass, while the compound containing amber glass shows similar compressive strength.

An improvement in the resistance to sulfate attack has also been observed [22, 23, 30-33], together with lower porosity of compounds, reduction in the width of the pore microstructure, a significantly lower chloride ion diffusion coefficient associated with improved resistance to chloride penetration, greater resistance to leaching of $\mathrm{Ca}$ ions, and lower shrinkage of concrete. Few studies have assessed the depth of carbonation in cementitious compounds manufactured with glasses and some of them address the use of waste as aggregate $[14,33,34]$. Studies on abrasion resistance are limited to assessing the effects of the use of waste glass to replace fine aggregates and the findings are contradictory $[35,36]$.

Though there are many studies on the use of microparticles in Portland cement compounds, there are still some points that need to be analyzed. The influence of glass color on the inhibition of alkali-aggregate reaction, on compressive strength, and on the abrasion resistance and electrical resistivity still need to be clarified.
TABLE 1: Physical and chemical characterization of colorless and amber glass microparticles.

\begin{tabular}{lcc}
\hline Item & Colorless & Amber \\
\hline Insoluble residue (\%) & 92.72 & 94.39 \\
Loss on ignition (\%) & 0.22 & 0.37 \\
Silicon dioxide & 73.93 & 72.95 \\
Calcium oxide & 9.18 & 9.28 \\
Aluminium oxide & 0.25 & 0.82 \\
Ferric oxide & 0.92 & 0.66 \\
Magnesium oxide & 3.75 & 3.58 \\
Sulphur trioxide & 0.23 & 0.25 \\
Sodium oxide & 9.18 & 5.99 \\
Potassium oxide & 0.02 & 0.02 \\
Alkali equivalent $(\%)$ & 9.19 & 6.00 \\
Specific mass $\left(\mathrm{g} / \mathrm{cm}^{3}\right)$ & 2.60 & 2.54 \\
Specific surface, BJH $\left(\mathrm{m}^{2} / \mathrm{kg}\right)$ & 4.265 & 4.918 \\
Specific surface, Blaine $\left(\mathrm{m}^{2} / \mathrm{kg}\right)$ & 371.8 & 366.3 \\
\hline
\end{tabular}

Preliminary results indicate that the use of colorless glass residue to replace cement decreases the permeability of the cementitious compound to oxygen, whereas it increases the thickness of carbonated layer, inhibits the alkali-silica reaction, and promotes the decrease of wear resistance [37]. In sequence, the present study evaluates indicators for the durability of a Portland cement composite made with the replacement of 10 and $20 \%$ of amber and colorless glass microparticles in comparison with a reference mortar. The tests performed were compressive strength, permeability to oxygen, accelerated carbonation, alkali-silica reaction, electrical resistivity, and wear resistance. As industrial glass waste of micrometric dimensions contains glasses of different chemical composition, flocculants, and dust, we have chosen, in this study, to produce the waste in the laboratory. This is, therefore, a preliminary study to support the use of microparticles produced by the glass drilling and processing industry in the production of Portland cement compounds.

\section{Materials and Methods}

The type of cement used was high initial resistance Portland cement. Glass wastes were produced in the laboratory to eliminate possible contaminants (Table 1). Each type of glass was collected from the industry in the form of plates, washed, dried, and submitted manually to a first reduction using ceramic balls. The pieces of glass were then crushed in a steel ball mill, with tempered steel balls. Glass composition and specific mass vary as a function of color, as described in the specific literature [38].

The values for particle size distribution of the glass microparticles obtained by light amplification by stimulated emission of radiation in a Cilas 92 particle sizer are presented in Table 2. Considering the specific surface (Table 1), it follows that types of the glass fineness are similar.

The X-ray diffraction of particles for both glasses showed diffuse spectra and absence of isolated peaks, typical of glass phases [18]. Shimadzu equipment, model XRD 7000s, was 
TABLE 2: Laser particle size distribution of colorless and amber glass microparticles.

\begin{tabular}{lcc}
\hline Percentages & Colorless $(\mu \mathrm{m})$ & Amber $(\mu \mathrm{m})$ \\
\hline $10 \%$ & $\leq 0.97$ & $\leq 1.07$ \\
$50 \%$ & $\leq 4.70$ & $\leq 5.65$ \\
$90 \%$ & $\leq 22.34$ & $\leq 28.35$ \\
Mean diameter & 8.93 & 10.61 \\
\hline
\end{tabular}

TABle 3: Modified Chapelle test results.

\begin{tabular}{lcccc}
\hline \multirow{2}{*}{ Glass microparticles } & \multicolumn{4}{c}{ Result } \\
& Sample 1 & Sample 2 & Sample 3 & Average \\
\hline Colorless & 565.83 & 580.42 & 540.13 & 562.13 \\
Amber & 645.06 & 670.43 & 650.12 & 655.20 \\
\hline
\end{tabular}

used for measurement, with a maximum output of $3 \mathrm{~kW}$, copper pipe, Theta-Theta goniometer with radius of 200 to $275 \mathrm{~mm}$, minimum step angle $0.0001^{\circ}$, operation angle range from -6 to +82 , slewing speed $500^{\circ} / \mathrm{min}$, scanning speed of $1^{\circ} / \mathrm{min}$, and distance of X-rays (axis) $85 \mathrm{~mm}$.

The pozzolanicity of the glasses was evaluated via modified Chapelle test (Table 3). In this test, the calcium hydroxide content is determined and fixed by a material in an aqueous medium [38]. The mean values of 562.13 and $655.20 \mathrm{mg}$ of $\mathrm{Ca}(\mathrm{OH})_{2} / \mathrm{g}$ considered in the samples analyzed are similar to the results reported by Bonneau et al. [39] for active silica (crushed quartz). Raverdy et al. [40] and coworkers established that the minimum intake of calcium hydroxide necessary for the material to present pozzolanic activity is $330 \mathrm{mg}$ of $\mathrm{Ca}(\mathrm{OH})_{2} / \mathrm{g}$ of the sample. We thus conclude that the microparticles possess pozzolanic activity.

For the production of mortar, natural silica sand was used as a fine aggregate, having specific mass of $2,650 \mathrm{~kg} / \mathrm{m}^{3}$ and containing equal proportions of particles sized 1.2, 0.6, 0.3 , and $0.15 \mathrm{~mm}$. The adopted proportion was of 1 binder (cement or cement + glass microparticles) to 3 of sand (with equal amounts of the four different particle sizes). The water/cement ratio was 0.5 . The mortars produced had an average workability of $210 \mathrm{~mm}$ in the spread test.

Compressive strength tests were carried out at 28 days on $5 \times 10 \mathrm{~cm}$ cylindrical test samples in a TC-PS 003 press with a load application of $0.5 \mathrm{MPa} / \mathrm{s}$, in conformity with ASTM C39/C39M-16b standard [41]. Three samples per compound have been tested.

Oxygen permeability tests were performed according to the recommendations of RILEM TC 116-PCD [42]. After 28 days of curing, the cylindrical mortar samples $(5 \mathrm{~cm}$ in height $\times 5 \mathrm{~cm}$ in diameter) were placed in an oven at $80^{\circ} \mathrm{C}$ for 24 hours for drying and were cooled prior to testing. The equipment used was a permeameter for measuring the gas flow through the confined porous material, subjected to a pressure differential between the points considered. Three tests were carried out for each type of mixture studied. Equation (1) is used to calculate the permeability of the sample and takes into account the compressibility and the viscosity of oxygen.

$$
k=\frac{4.04 Q P_{2} L}{A\left(P_{1}^{2}-P_{2}^{2}\right)} 10^{-16},
$$

where $k$ denotes intrinsic permeability $\left(\mathrm{m}^{2}\right) ; L$ denotes the length of the sample $(\mathrm{m})$; $A$ denotes the cross sectional area of the sample $\left(\mathrm{m}^{2}\right) ; Q$ denotes the flow rate $\left(\mathrm{cm}^{3} / \mathrm{s}\right) ; P_{1}$ denotes the absolute pressure applied (in bar); and $P_{2}$ denotes the pressure flow (in bar). According to this equation, the larger the coefficient, the higher the rate of permeation of the fluid through the mortar due to the pressure difference.

Carbonation resistance was carried out in a climatecontrolled Thermo Fisher Scientific Chamber, model 3000T RCO-5-VBC, according to the recommendations of RILEM TC 116-PCD [42]. Cylindrical samples of $5 \mathrm{~cm}$ in diameter $\times 10 \mathrm{~cm}$ in height were produced for each type of mixture. The samples were immersed in water and cured for 28 days. After curing, the surfaces were brushed and rinsed to remove residues that could hinder the diffusion of carbon dioxide inside the cement compounds. The samples were then dried in an oven and exposed for 60 days to an atmosphere containing $5 \%$ of $\mathrm{CO}_{2}$, of $48 \%$ humidity, and temperature of $27.5^{\circ} \mathrm{C} \pm 2$. The samples were then sectioned longitudinally and the carbonation depth determined from spraying a solution of $70 \%$ absolute ethanol, $29 \%$ distilled water, and $1 \%$ phenolphthalein. Using a digital vernier caliper with accuracy of $0.01 \mathrm{~mm}$, three measurements were performed on each sample.

The electrical resistivity test was carried out to evaluate the probability and intensity of the corrosion of the reinforcing bars in reinforced concrete due to chloride action [43, 44]. The electrical resistivity of the cementitious compounds was calculated by measuring the volumetric resistivity in a saturated condition, by means of electrodes positioned on opposite sides of the samples, to which a potential difference was applied, measuring the current generated between them $[45,46]$. For each type of mixture, $5 \times 10 \mathrm{~cm}$ cylindrical samples made of mortars with and without addition of glass microparticles were cast and cured for 28 days. After 24 hours of saturation in clean water, the samples were pressed in the longitudinal direction against two copper plates (electrodes). In order to maximize contact, steel wool was inserted between the plates and the ends of the samples. Using an alternating current source with sinusoidal waves and varying frequencies $(10-7500 \mathrm{~Hz})$, a potential difference was applied (between 2 and $8 \mathrm{~V}$ ). A standard frequency of $50 \mathrm{~Hz}$ was established for the tests.

For the evaluation tests of the alkali-aggregate reaction, prismatic samples of $25 \times 25 \times 250 \mathrm{~cm}$ were produced for each type of compound. For the alkali-silica reaction tests, sand produced by crushing and grinding basalt rocks was used as indicated by ASTM C1260-14 [47]. The proportion was $1: 2.25$ (cement/sand) by mass and the water-cement ratio 0.47 . The tests were performed at a temperature of $80^{\circ} \mathrm{C}$. The expansion thresholds were measured at 16 days and scheduled dates $(0$, $3,6,10,19$, and 30 days), and the final value was calculated using the average of three bars for each age. 


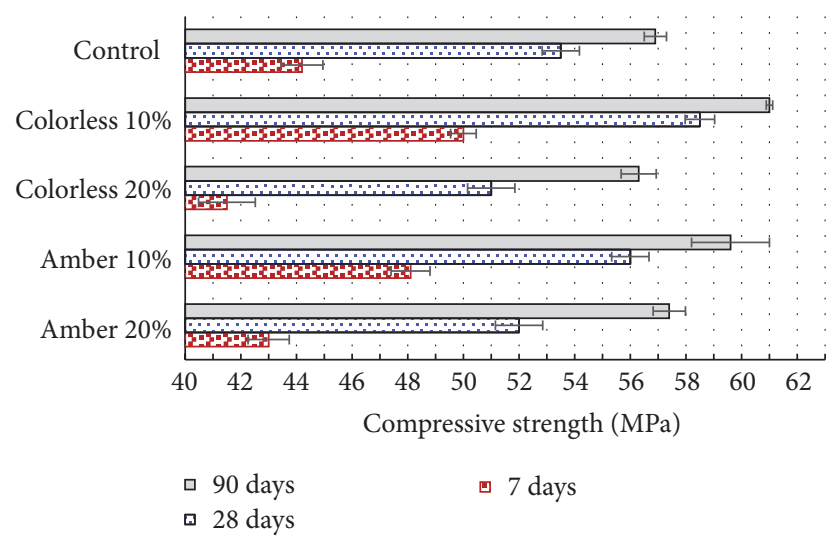

FIGURE 1: Mortar compressive strength results (average values and standard deviations).

For abrasion resistance, prismatic samples measuring 70 $\times 70 \times 30 \mathrm{~mm}$ have been prepared. The test was carried out using Amsler equipment. ASTM C 418-12 [48] was used as reference. After 28 days of curing, the samples were submitted to wear with quartz sand under a load of approximately $66 \mathrm{~N}$ at a rate of $(30 \pm 1) \mathrm{rpm}$. Measurements were performed after 500 laps, which corresponds to 1000 meters. After 500 meters, the samples were placed upside down on the coupling device support in such a way as to avoid distortion (skewness) of the material. After the course, the reduction in the thickness of the four sides of the samples was measured to evaluate wear.

Scanning electronic microscopy (SEM) was used to evaluate the morphology of the samples on a Quanta 200-FEGFEI in high vacuum. Energy dispersive spectroscopy (EDS) linked to the SEM microscope was used to confirm the composition of the nanoparticles.

\section{Results and Discussion}

3.1. Compressive Strength Tests. Figure 1 shows the average values and standard deviations of measurements obtained in the composite compressive strength tests with and without the use of glass microparticles. The addition of $10 \%$ colorless or amber glass is associated with a slight increase of the mechanical strength of samples. The addition of $20 \%$ glass has a lower influence on the compressive strength of compounds. The same trends are observed in all the ages. According to Dyer and Dhir [29], using 10 or $20 \%$ of amber glass particles ( $44 \%$ mass retained on the $45 \mu \mathrm{m}$ sieve) to replace cement does not affect the resistance to compression of mortars at 7 and 28 days.

Khmiri et al. [17] showed that only at 90 days does the compressive strength of mortars with $20 \%$ substitution of the cement by glass particles of $20 \mu \mathrm{m}$ present values close to compounds cast without glass. Calmon at al. [49] observed a reduction in compressive strength when $10-20 \%$ of the cement was replaced by waste glass from windshields. They associated this effect to the cracking of the matrix due to the formation of calcium sulphoaluminate at later ages, caused by the alumina content $(5 \%)$ in the mixture, introduced by the glass. As the glasses analyzed in this work possessed

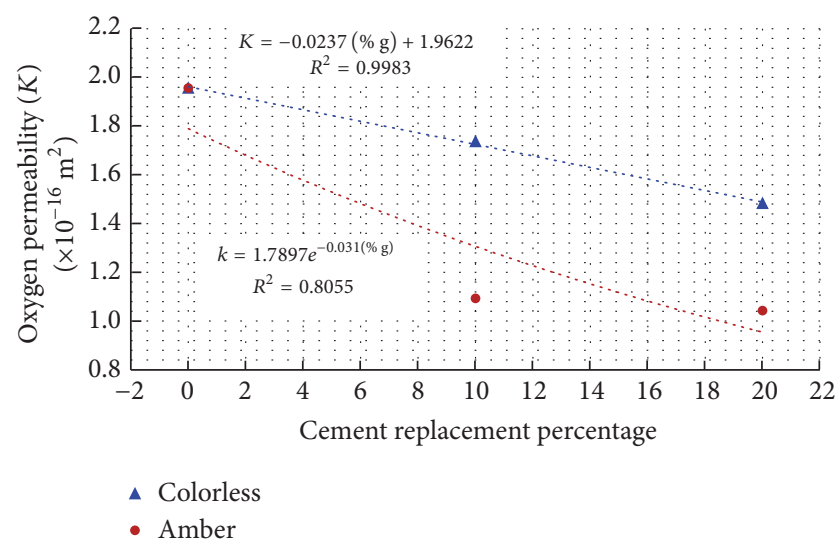

FIGURE 2: Results of oxygen permeability test after 60 days of curing.

an alumina content of 0.25 to $0.82 \%$, this microcracking did not occur. In general, the slowness of the hydration reactions observed when $20 \%$ glass microparticles were used provides evidence of their pozzolanic nature.

3.2. Oxygen Permeability Tests. Figure 2 shows the measured and average values for the permeability coefficient for oxygen (bars) after 60 days of curing. The result was calculated from (1) for samples with and without partial replacement of cement by glass. According to Lee et al. [50] in regard to the durability, a concrete with coefficient of permeability to oxygen below $1 \times 10^{-16} \mathrm{~m}^{2}$ is considered good; between $1 \times$ $10^{-16}$ and $3 \times 10^{-16} \mathrm{~m}^{2}$ is moderate, and above $3 \times 10^{-16} \mathrm{~m}^{2}$ is considered poor. By extrapolating the above information for mortar, it was found that the use of colorless glass microparticles in replacement of cement did not alter the durability classification of cementitious compounds: moderate. The experimental data showed significant dispersion. However, the statistical analysis of the data by means of Analysis of Variance (ANOVA) indicated that the use of glass microparticles in replacement of cement contributes to reducing permeability and that this influence is independent of the chemical characteristics of glass microparticles. Jain and Neithalath [32] and Calmon et al. [49] studied cement pastes with and without microparticles and found that the glass particles replacement led to smaller porosity. Probably, the permeability improvement was due to the chemical composition and the structure of the noncrystalline silica, which favors the occurrence of a pozzolanic reaction, when the glass is put into contact with calcium hydroxide. The reaction products reduce the width of the pores, increase the tortuosity in the pore network, and reduce pore connectivity $[33,51]$.

This reduction in permeability does not result in an increase in compressive strength. This could be related to the fact that the glass microparticles might also be acting as filler, the void filling mechanism having less effect on mechanical strength, which depends strongly on the slow pozzolanic reaction.

3.3. Accelerated Carbonation Test. Figure 3 shows the mean results of the accelerated carbonation test and their standard 


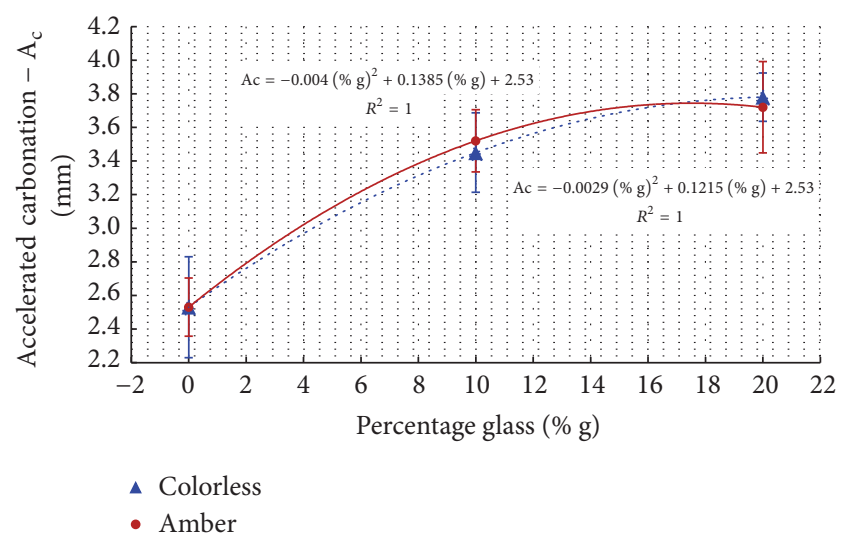

Figure 3: Accelerated carbonation test results, 60 days.

deviations after 60 days in a carbonation chamber. It was observed that all samples suffered carbonation after 60 days. The addition of glass microparticles increased the thickness of the carbonated layer by $1.3 \mathrm{~mm}$ when compared with the control sample. It was also remarked that the larger the glass content, the greater the carbonation depth. It was not possible to identify the effects of the nature (color) of the glass microparticles (differences of $0.25 \mathrm{~mm}$ and similar trend lines). It should be noted that the rates of carbonation gain were small. This could be related to the fact that the samples were stored at $48 \%$ humidity, as this low humidity condition could impede the diffusion of $\mathrm{CO}_{2}$ in the pores. The fastest carbonation rates occur at relative humidity between 50 and $75 \%$, as reported in studies by Parrot [52] and De Ceukelaire and Van Nieuwenburg [53].

3.4. Tests of the Alkali-Aggregate Reaction. The average results of the three measurements and the respective standard deviations of the corresponding measurements obtained from the alkali-silica reaction test are shown in Figure 4. According to ASTM C 1260-14 [47], an expansion below 0.10 and higher than $0.20 \%$ at 16 days may indicate respectively aggregates with innocuous and reactive behaviors. Expansions between 0.10 and $0.20 \%$ are considered potentially reactive. Thus, it was decided to take the test to up to 30 days. After 16 days, the sample containing $20 \%$ amber glass remained in the nonreactive class. The samples with 10 and $20 \%$ colorless glass microparticles and $10 \%$ amber glass remained in class II, namely, potentially reactive material. At 30 days, the use of $20 \%$ amber glass classifies the material as II. All other mixtures changed to a higher class of alkali-silica reaction, being in the range of potentially reactive materials. Results of Kara [54] show that the lower expansion due to alkalisilica reaction occurs when the cement was replaced by $30 \%$ of amber glass particles (Blaine of $542 \mathrm{~m}^{2} / \mathrm{kg}$ ). It was evident that the use of amber glass microparticles can inhibit alkalisilica reactions even when highly reactive aggregates are used. Recently, similar results were obtained by Cociña et al. [10] and Serpa et al. [55].

The results of several publications indicate that the use of glass microparticles as supplementary cementitious material

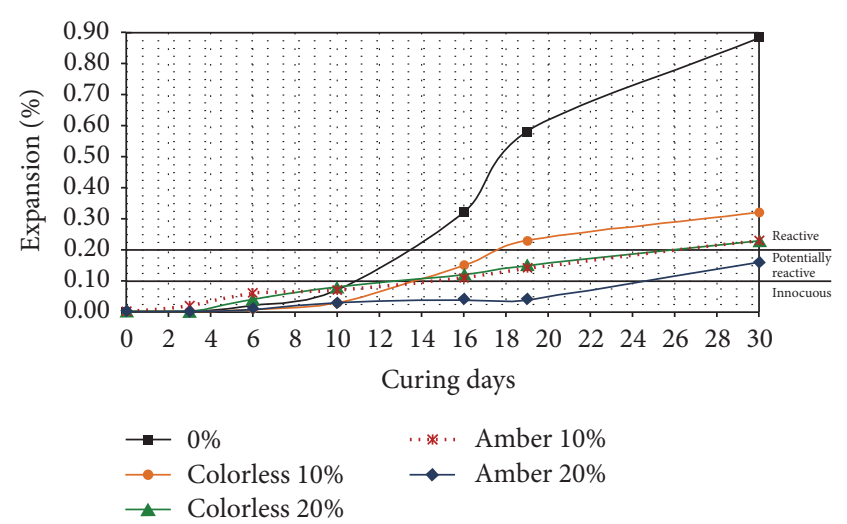

FIGURE 4: Alkali-silica reaction test results.

is effective in reducing the expansion of the alkali-silica reaction $[4,5,56,57]$. This could indicate that the alkalis present in glass in quantities greater than those recommended for pozzolanic materials became inert or did not contribute to the occurrence of the alkali-silica reaction. According to the literature, the silica present in microparticles promotes the increase of calcium-silicate-hydrate content in the mixture due to the pozzolanic reaction. This can turn the paste denser and, consequently, less porous and permeable, hindering the movement of alkalis and the alkali-silica reaction [58, 59]. The present results indicate that the permeability of the paste changed with the use of glass microparticles. Another possible explanation for the inhibition of the alkali-silica reaction with the use of glass particles is that the hydrated calcium silicate formed by the pozzolanic reaction leads to increased paste strength, which is then able to withstand the expansive stresses associated with the alkali-silica reaction [58]. On the other hand, the pozzolanic reaction produces silicates of low $\mathrm{CaO} / \mathrm{SiO}_{2}$ ratio, which are able to encapsulate part of the alkalis that thus become unable to react [59-61]. Other hypotheses addressed in published studies concern the reduced viscosity of expansive gel in media with high $\mathrm{Na} / \mathrm{Si}$ ratio or the nonpolymerization of the alkali-silica reaction product in a medium of high alkalinity [62].

3.5. Volumetric Electrical Resistivity Test. Mean values and standard deviations relative to electrical resistivity tests at 28 days are shown in Figure 5. Results of the same order of magnitude were found by Carsana et al. [63] in a 28-day study of mortars with and without replacement of cement by fine glass powder derived from green bottles (30\%).

An important parameter for evaluating the durability of concrete in relation to the action of the chloride ion is the concrete electrical resistivity, since this variable is sensitive to the flow of ions diffused in the cementitious compounds, through the water present in the pores. According to Gowers and Millard [64], the ionic flow between the anode and the cathode regions of the reinforcement is regulated by the concrete electrical resistance. The lower the resistivity of the concrete, the higher the electrical current between anode and the cathode and the speed of reinforcement corrosion. Hence, it is possible to evaluate the risk of corrosion of 
TABLE 4: Average thickness loss values obtained by abrasion test $(1000 \mathrm{~m})$.

\begin{tabular}{lccccc}
\hline Age & Control & \multicolumn{3}{c}{ Percentage values } \\
& & Colorless 10\% & Amber 10\% & Colorless 20\% & Amber 20\% \\
\hline $\begin{array}{l}\text { 28 days } \\
\begin{array}{l}\text { Standard } \\
\text { deviation }\end{array}\end{array}$ & 2.34 & 5.53 & 5.43 & 6.90 & 7.74 \\
\hline
\end{tabular}

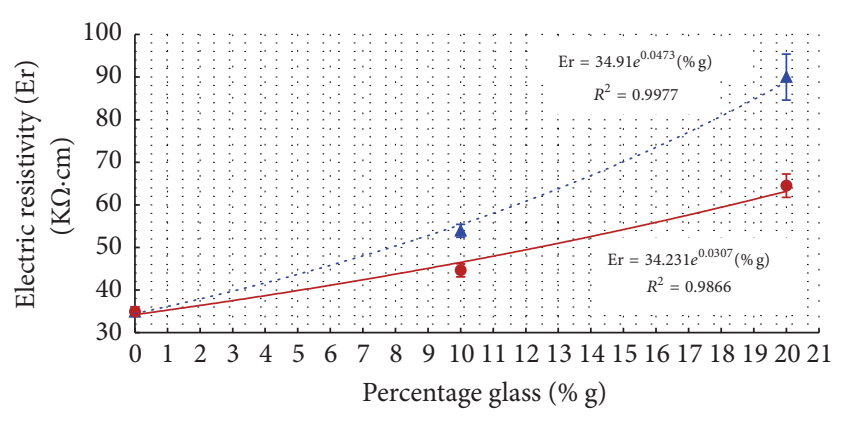

Colorless

- Amber

FIGURE 5: Results of electrical resistivity test in mortars, 28 days.

the reinforcement by measurement of electrical resistivity of concrete. According to Whiting and Nagi [44], a very high reinforcement corrosion risk range has concrete resistivities below $5 \mathrm{k} \Omega \cdot \mathrm{cm}$. While a high corrosion risk range is between 5 and $10 \mathrm{~K} \Omega \cdot \mathrm{cm}$, moderate to low corrosion risk is between 10 and $20 \mathrm{~K} \Omega \cdot \mathrm{cm}$ and low corrosion risk is above $20 \mathrm{k} \Omega \cdot \mathrm{cm}$. According to the European Concerted Action EC-COST 509 [65], a high reinforcement corrosion risk range corresponds to resistivity values below $10 \mathrm{k} \Omega \mathrm{cm}$, while the range of moderate corrosion risk is between 10 and $50 \mathrm{~K} \Omega \cdot \mathrm{cm}$, low corrosion risk range is between 50 and $100 \mathrm{k} \Omega \cdot \mathrm{cm}$, and insignificant corrosion risk range is above $100 \mathrm{k} \Omega \cdot \mathrm{cm}$. Hoppe [66] and Lübeck [67] underscore the high sensitivity of resistivity to various intrinsic factors such as water/binder ratio, consumption and type of cement, and aggregate and mineral admixtures, as they promote changes in the pore size and distribution, internal moisture content, and $\mathrm{pH}$, among others, and thus decrease the corrosion rate. The values obtained reveal that the samples with and without glass microparticles are within the moderate/low corrosion risk range. Nevertheless, samples containing glass microparticles-particularly colorless glass-are more resistant to reinforcement corrosion. The increase in resistivity due to the use of glass microparticles can be explained by the fact that, within the concrete containing glass, the ion flow is lower due to the pozzolanic reaction, which consumes $\mathrm{Ca}^{2+}$ and $\mathrm{OH}^{-}$, or as a result of the change in pore structure due to the pozzolanic reaction. According to Hunkeler [68], the increased resistivity of the pore solution and a smaller fraction of the conductive phase, calcium hydroxide, explain the higher resistivity of concrete with pozzolanic additions. The higher resistivity due to the use of pozzolans may also be due to the reduction in width and increased tortuosity of the pore network, thus hindering ion mobility and interaction [50].
3.6. Abrasion Resistance Tests. The results of the test for resistance to wear by abrasion after 1,000 meters are shown in Table 4, where the average values of loss of thickness of three samples are presented. These values were measured at four points across the sample after 28 days of curing in a humid chamber and the test was performed at 90 days. Cement replacement with 10 to $20 \%$ of colorless and amber glass microparticles was seen to have reduced wear resistance. We can therefore note that both the type and the amount of glass used influenced this result. These data reveal that a weaker layer was formed on the concrete surface, probably due to the higher exudation and accentuated by the presence of glass particles [69]. The experimental results found by Nassar and Soroushian [16] show that the abrasion resistance of mortars made with $23 \%$ of ground waste glass $(25 \mu \mathrm{m})$ in replacement of concrete increases with the percentage of substitution.

3.7. Analysis of the Microstructure. Figure 6 shows the microstructures of compounds with and without the replacement of glass microparticles. These microstructures were amplified 350 times and were obtained by means of a backscattered electron detector. A higher magnification was adopted in such a way as to achieve a more general description of the microstructure of the analyzed material. The presence of quartz was observed in all samples (by energy dispersive spectroscopy) probably due to the type of sand used.

In all the samples the presence of calcium hydroxide, calcium carbonate, tricalcium silicate, aluminium and calcium hydrosulphate, tetracalcium sulphoaluminate, and hydrated calcium silicate was detected, all of them normal constituents of Portland cement paste [70]. As suggested by Matos and Coutinho [2] there were no glass particles in the paste. Sobolev et al. [71] have found that mortars containing glass particles in partial replacement of cement have smaller crystals and low calcium hydroxide content as compared to mortars made only with cement, due to the occurrence of the pozzolanic reaction, which could contribute towards greater durability of the compound [69]. Even with large amplifications of the analyzed images, it has not been possible to observe differences in the size of sodium hydroxide crystals identified by EDS.

\section{Conclusions}

(i) The replacement of 10 and $20 \%$ of the cement content with amber and colorless glass microparticles helps reduce the oxygen permeability of the compounds.

(ii) The use of $20 \%$ amber glass microparticles observed in the samples resulted in the lowest oxygen 


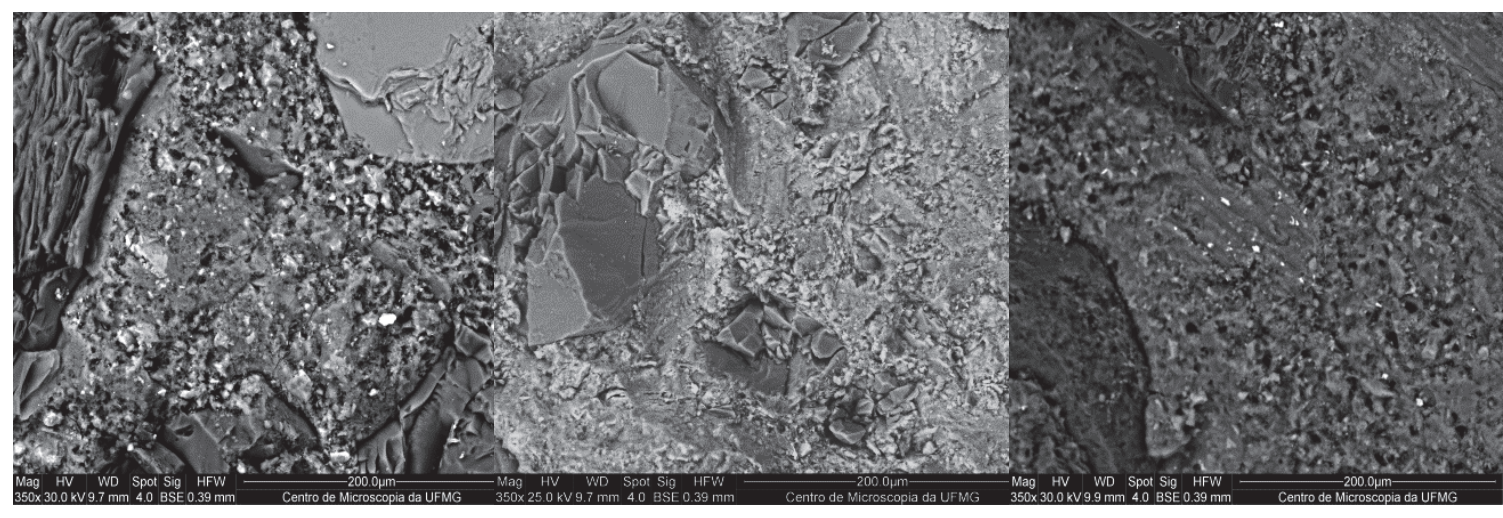

Glass 0\%

Colorless $10 \%$

Colorless $20 \%$

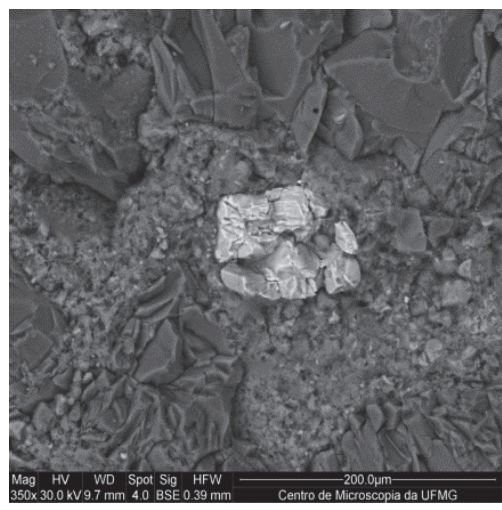

Amber $10 \%$

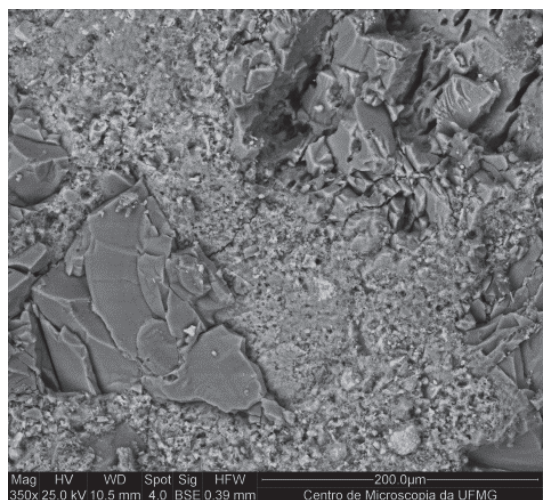

Amber $20 \%$

FiguRE 6: Images obtained by scanning electron microscopy (backscattered electrons) for samples with and without the replacement of glass microparticles.

permeability, indicating that the chemical and physical characteristics of amber glass (and in greater quantity) can contribute to a lower open porosity of the mixture.

(iii) When compared with the control sample, the thickness of the carbonated layer in samples with glass microparticles increased.

(iv) Glass microparticles inhibit alkali-silica reactions even with the use of reactive aggregates. This effect was more marked when the replacement was $20 \%$ of amber glass.

(v) The high silica content present in the glass did not promote the cement alkali-silica reaction, possibly due to the specific surface and the amorphous nature of the silica, which caused the silica to react with calcium hydroxide at early ages, with no silica content for later reactions.

(vi) The values for concrete electrical resistivity revealed that samples with and without glass microparticles were within the moderate/low reinforcement corrosion risk range. However, samples containing glass microparticles were observed to be more resistant to corrosion risk, in particular those made of colorless glass. (vii) The use of colorless and amber glass microparticles promoted a reduction in wear resistance due to increased exudation itself possibly due to the presence of glass particles. The higher the level of cement replacement with glass, the higher the reduction in wear resistance. This reduction is more marked when amber glass is used.

\section{Conflicts of Interest}

The authors declare that they have no conflicts of interest.

\section{Acknowledgments}

This work was supported by the Coordination for the Improvement of Higher Education Personnel (CAPES); the Research Support Foundation of the State of Minas Gerais (FAPEMIG); and the National Council for Scientific and Technological Development (CNPq).

\section{References}

[1] E. M. Gartner and D. E. MacPhee, "A physico-chemical basis for novel cementitious binders," Cement and Concrete Research, vol. 41, no. 7, pp. 736-749, 2011. 
[2] A. M. Matos and J. S. Coutinho, "Durability of mortar using waste glass powder as cement replacement," Construction and Building Materials, vol. 36, pp. 205-215, 2012.

[3] B. Lothenbach, K. Scrivener, and R. D. Hooton, "Supplementary cementitious materials," Cement and Concrete Research, vol. 41, pp. 217-229, 2011.

[4] M. Thomas, "The effect of supplementary cementing materials on alkali-silica reaction: a review," Cement and Concrete Research, vol. 41, pp. 209-216, 2011.

[5] K. L. Scrivener and A. Nonat, "Hydration of cementitious materials, present and future," Cement and Concrete Research, vol. 41, pp. 651-665, 2011.

[6] Y. Li and A. K. H. Kwan, "Ternary blending of cement with fly ash microsphere and condensed silica fume to improve the performance of mortar," Cement and Concrete Composites, vol. 49, pp. 26-35, 2014.

[7] V. Lilkov, I. Rostovsky, O. Petrov et al., "Long term study of hardened cement pastes containing silica fume and fly ash," Construction and Building Materials, vol. 60, pp. 48-56, 2014.

[8] M. E. I. Saraya, "Study physico-chemical properties of blended cements containing fixed amount of silica fume, blast furnace slag, basalt and limestone, a comparative study," Construction and Building Materials, vol. 72, pp. 104-112, 2014.

[9] J. H. S. Rêgo, A. A. Nepomuceno, E. P. Figueiredo, and N. P. Hasparyk, "Microstructure of cement pastes with residual rice husk ash of low amorphous silica content," Construction and Building Materials, vol. 80, pp. 56-68, 2015.

[10] E. V. Cociña, J. H. Ruiz, M. Frías, and H. Savastano, "Pozzolanic behaviour of a bagasse ash from the boiler of a Cuban sugar factory," Advances in Cement Research, vol. 25, no. 3, pp. 136142, 2013.

[11] H. Du and K. H. Tan, "Use of waste glass as sand in mortar: Part II: Alkali-silica reaction and mitigation methods," Cement and Concrete Composites, vol. 35, no. 1, pp. 118-126, 2013.

[12] R. Idir, M. Cyr, and A. Tagnit-Hamou, "Pozzolanic properties of fine and coarse color-mixed glass cullet," Cement and Concrete Composites, vol. 33, no. 1, pp. 19-29, 2011.

[13] G. Lee, C. S. Poon, Y. L. Wong, and T. C. Ling, "Effects of recycled fine glass aggregates on the properties of dry-mixed concrete blocks," Construction and Building Materials, vol. 38, pp. 638-643, 2013.

[14] S. Nunes, A. M. Matos, T. Duarte, H. Figueiras, and J. SousaCoutinho, "Mixture design of self-compacting glass mortar," Cement and Concrete Composites, vol. 43, pp. 1-11, 2013.

[15] C. D. Johnston, "Waste glass as coarse aggregate for concrete," Journal of Testing and Evaluation, vol. 2, no. 5, pp. 344-350, 1974.

[16] R.-U. Nassar and P. Soroushian, "Strength and durability of recycled aggregate concrete containing milled glass as partial replacement for cement," Construction and Building Materials, vol. 29, pp. 368-377, 2012.

[17] A. Khmiri, M. Chaabouni, and B. Samet, "Chemical behaviour of ground waste glass when used as partial cement replacement in mortars," Construction and Building Materials, vol. 44, pp. 74-80, 2013.

[18] C. H. Chen, R. Huang, J. K. Wu, and C. C. Yang, "Waste e-glass particles used in cementitious mixtures," Cement and Concrete Research, vol. 36, no. 3, pp. 449-456, 2006.

[19] S. H. Liu, G. S. Xie, and S. Wang, "Effect of curing temperature on hydration properties of waste glass powder in cement-based materials," Journal of Thermal Analysis and Calorimetry, vol. 119, no. 1, pp. 47-55, 2015.
[20] R. K. Dhir, T. D. Dyer, and M. C. Tang, "Alkali-silica reaction in concrete containing glass," Materials and Structures, vol. 42, no. 10, pp. 1451-1462, 2009.

[21] R. Idir, M. Cyr, and A. Tagnit-Hamou, "Use of fine glass as ASR inhibitor in glass aggregate mortars," Construction and Building Materials, vol. 24, no. 7, pp. 1309-1312, 2010.

[22] A. Shayan and A. Xu, "Performance of glass powder as a pozzolanic material in concrete: a field trial on concrete slabs," Cement and Concrete Research, vol. 36, no. 3, pp. 457-468, 2006.

[23] Y. Shao, T. Lefort, S. Moras, and D. Rodriguez, "Studies on concrete containing ground waste glass," Cement and Concrete Research, vol. 30, no. 1, pp. 91-100, 2000.

[24] C. Shi, Y. Z. Wu, C. Riefler, and H. Wang, "Characteristics and pozzolanic reactivity of glass powders," Cement and Concrete Research, vol. 35, no. 5, pp. 987-993, 2005.

[25] I. B. Topcu, A. R. Boga, and T. Bilir, "Alkali-silica reactions of mortars produced by using waste glass as fine aggregate and admixtures such as fly ash and $\mathrm{Li}_{2} \mathrm{CO}_{3}$," Waste Management, vol. 28, no. 5, pp. 878-884, 2008.

[26] N. Schwarz, H. Cam, and N. Neithalath, "Influence of a fine glass powder on the durability characteristics of concrete and its comparison to fly ash," Cement and Concrete Composites, vol. 30, no. 6, pp. 486-496, 2008.

[27] A. Karamberi and A. Moutsatsou, "Participation of coloured glass cullet in cementitious materials," Cement and Concrete Composites, vol. 27, no. 2, pp. 319-327, 2005.

[28] M. Mirzahosseini and K. A. Riding, "Effect of curing temperature and glass type on the pozzolanic reactivity of glass powder," Cement and Concrete Research, vol. 58, pp. 103-111, 2014.

[29] T. D. Dyer and R. K. Dhir, "Chemical reactions of glass cullet used as cement component," Journal of Materials in Civil Engineering, vol. 13, no. 6, pp. 414-417, 2001.

[30] Z. Wang, C. Shi, and J. Song, "Effect of glass powder on chloride ion transport and alkali-aggregate reaction expansion of lightweight aggregate concrete," Journal Wuhan University of Technology, Materials Science Edition, vol. 24, no. 2, pp. 312-317, 2009.

[31] J. Jain and N. Neithalath, "Analysis of calcium leaching behavior of plain and modified cement pastes in pure water," Cement and Concrete Composites, vol. 31, no. 3, pp. 176-185, 2009.

[32] J. A. Jain and N. Neithalath, "Chloride transport in fly ash and glass powder modified concretes-influence of test methods on microstructure," Cement and Concrete Composites, vol. 32, no. 2, pp. 148-156, 2010.

[33] S. de Castro and J. de Brito, "Evaluation of the durability of concrete made with crushed glass aggregates," Journal of Cleaner Production, vol. 41, no. 1, pp. 7-14, 2013.

[34] F. G. Da Silva, P. Helene, P. Castro-Borges, and J. B. L. Liborio, "Sources of variations when comparing concrete carbonation results," Journal of Materials in Civil Engineering, vol. 21, no. 7, pp. 333-342, 2009.

[35] P. Turgut and E. S. Yahlizade, "Research into concrete blocks with waste glass," International Journal of Civil Engineering, vol. 1, no. 4, pp. 203-209, 2009.

[36] N. Su and J. S. Chen, "Engineering properties of asphalt concrete made with recycled glass," Resources, Conservation and Recycling, vol. 35, no. 4, pp. 259-274, 2002.

[37] F. A. Sales et al., "Study of durability of mortar for structural concrete made with fine powder of white glass," in Proceedings of the XIII Int Conf Dur Build Mat Comp, vol. 9, pp. 984-993, São Paulo, Brazil, 2014. 
[38] G. Chen, H. Lee, K. L. Young et al., "Glass recycling in cement production: an innovative approach," Waste Management, vol. 22, no. 7, pp. 747-753, 2002.

[39] O. Bonneau, C. Vernet, M. Moranville et al., "Characterization of the granular packing and percolation threshold of reactive powder concrete," Cement and Concrete Research, vol. 30, no. 12, pp. 1861-1867, 2000.

[40] M. Raverdy, F. Brivot, A. M. Paillere, and R. Dron, "Appréciation de l'actvité pouzzolanique dos constituants secondaires," in Proceedings of the 7th International Congress on the Chemistry of Cement, vol. 3, pp. 36-41.

[41] ASTM C39/C39M-16b, Standard test method for compressive strength of cylindrical concrete specimens, ASTM International, West Conshohocken, Pa, USA.

[42] RILEM, "Recommendations of TC 116-PCD. Tests for gas permeability of concrete," Materials and Structures, vol. 32, no. 217, pp. 163-179, 1999.

[43] O. Sengul and O. E. Gjørv, "Electrical resistivity measurements for quality control during concrete construction," ACI Materials Journal, vol. 105, no. 6, pp. 541-547, 2008.

[44] D. A. Whiting and M. A. Nagi, Electrical resistivity of concrete: a literature review. $R$ \& $D$ Serial $n$. 2457, Portland Cement Association, Skokie, Illinois, USA, 2003.

[45] CEI 93-Commission Electrotechnique International, Méthodes pour la mesure de la résistivité transversale et da le résistivité superficielle des matériaux isolants électriques solides, 2nd edition, 1980.

[46] R. P. Spragg, J. Castro, T. Nantung et al., Variability analysis of the bulk resistivity measured using concrete cylinders. Publication FHWA/IN/JTRP-2011/21. Joint transp res program, Indiana, Dep Transp and Purdue Univ, West Lafayette, Ind, USA, 2011.

[47] ASTM C1260-14, Standard Test Method for Potential Alkali Reactivity of Aggregates (Mortar-Bar Method), ASTM International, West Conshohocken, PA, USA, 2014.

[48] ASTM C418-12, Standard Test Method for Abrasion Resistance of Concrete by Sandblasting, ASTM International, West Conshohocken, PA, USA, 2012.

[49] J. L. Calmon, A. S. Sauer, G. L. Vieira, and J. E. S. L. Teixeira, "Effects of windshield waste glass on properties of repair mortars," Cement and Concrete Composites, vol. 53, pp. 88-96, 2014.

[50] C. Y. Lee, M. J. McCarthy, and R. K. Dhir, "Intrinsic permeability of fly ash concrete," in Proceedings of 4th Int Conf Durab Concr, V. M. Malhotra, Ed., vol. 2, pp. 247-266, Sydney, 1997.

[51] W. J. McCarter and D. Tran, "Monitoring pozzolanic activity by direct activation with calcium hydroxide," Construction and Building Materials, vol. 10, no. 3, pp. 179-184, 1996.

[52] L. J. Parrot, "A review of carbonation in reinforced concrete," $C$ \& CA - Cement and Concrete Association, p. 42, 1987.

[53] L. De Ceukelaire and D. Van Nieuwenburg, "Accelerated carbonation of a blast-furnace cement concrete," Cement and Concrete Research, vol. 23, no. 2, pp. 442-452, 1993.

[54] P. Kara, "The influence of waste glass slurry on the properties of concrete," International Journal of Application or Innovation in Engineering \& Management, vol. 2, no. 8, pp. 325-330, 2013.

[55] D. Serpa, A. Santos Silva, J. De Brito, J. Pontes, and D. Soares, "ASR of mortars containing glass," Construction and Building Materials, vol. 47, pp. 489-495, 2013.

[56] M. Cyr, P. Rivard, and F. Labrecque, "Reduction of ASRexpansion using powders ground from various sources of reactive aggregates," Cement and Concrete Composites, vol. 31, no. 7, pp. 438-446, 2009.
[57] S. Diamond and N. Thaulow, "A study of expansion due to alkali-silica reaction as conditioned by the grain size of the reactive aggregate," Cement and Concrete Research, vol. 4, no. 4, pp. 591-607, 1974.

[58] J. Duchesne and M. A. Bérubé, “The effectiveness of supplementary cementing materials in suppressing expansion due to ASR: Another look at the reaction mechanisms part 1: Concrete expansion and portlandite depletion," Cement and Concrete Research, vol. 24, no. 1, pp. 73-82, 1994.

[59] G. J. Z. Xu, D. F. Watt, and P. P. Hudec, "Effectiveness of mineral admixtures in reducing ASR expansion," Cement and Concrete Research, vol. 25, no. 6, pp. 1225-1236, 1995.

[60] F. P. Glasser, "Chemistry of alkali-aggregate reaction," in The Alkali-Silica Reaction in Concrete, R. Swamy, Ed., pp. 30-53, Van Nostrand Reinhold, New York, NY, USA, 1998.

[61] S. Y. Hong and F. P. Glasser, "Alkali binding in cement pastes Part I: the C-S-H phase," Cement and Concrete Research, vol. 29, no. 12, pp. 1893-1903, 1999.

[62] R. Helmuth, D. Stark, S. Diamond, and M. Moranville-Regourd, Alkali-Silica Reactivity: an Overview of Research, Strategic Highway Research Program - SHRP, Washington, DC, USA, 1993.

[63] M. Carsana, M. Frassoni, and L. Bertolini, "Comparison of ground waste glass with other supplementary cementitious materials," Cement and Concrete Composites, vol. 45, pp. 39-45, 2014.

[64] K. R. Gowers and S. G. Millard, "Measurement of concrete resistivity for assessment of corrosion severity of steel using Wenner technique," ACI Materials Journal, vol. 96, no. 5, pp. 536-541, 1999.

[65] European Concerted Action COST 509, "Corrosion and protection of metals in contact with concrete: part 2. Monitoring," Final Report, European Commission, Brussel, Belgium, 1997.

[66] T. F. Hoppe, Resistividade elétrica de concretos contendo diferentes teores de cinza de casca de arroz [M.S. thesis], UFSM, Santa Maria, 2005.

[67] A. Lübeck, Resistividade elétrica de concreto de cimento Portland branco e elevados teores de escoria de alto forno [M.S. thesis], UFSM, Santa Maria, 2008.

[68] F. Hunkeler, "The resistivity of pore water solution: a decisive parameter of rebar corrosion and repair methods," Construction and Building Materials, vol. 10, no. 5, pp. 381-389, 1996.

[69] P. K. Mehta and P. J. M. Monteiro, Concrete: Microstructure, Properties, and Materials, McGraw-Hill Education, New York, NY, USA, Fourth Edition edition, 2014.

[70] M. Fuentes, A. Zúñiga, M. Díaz, E. Rocha, and S. Díaz, "Molienda mecánica por alta energía de minerales mexicanos para producir concreto de alto desempeño (CAD)," Revista ingeniería de construcción, vol. 29, no. 3, pp. 256-269, 2014.

[71] K. Sobolev, P. Türker, S. Soboleva, and G. Iscioglu, "Utilization of waste glass in ECO-cement: Strength properties and microstructural observations," Waste Management, vol. 27, no. 7, pp. 971-976, 2007. 

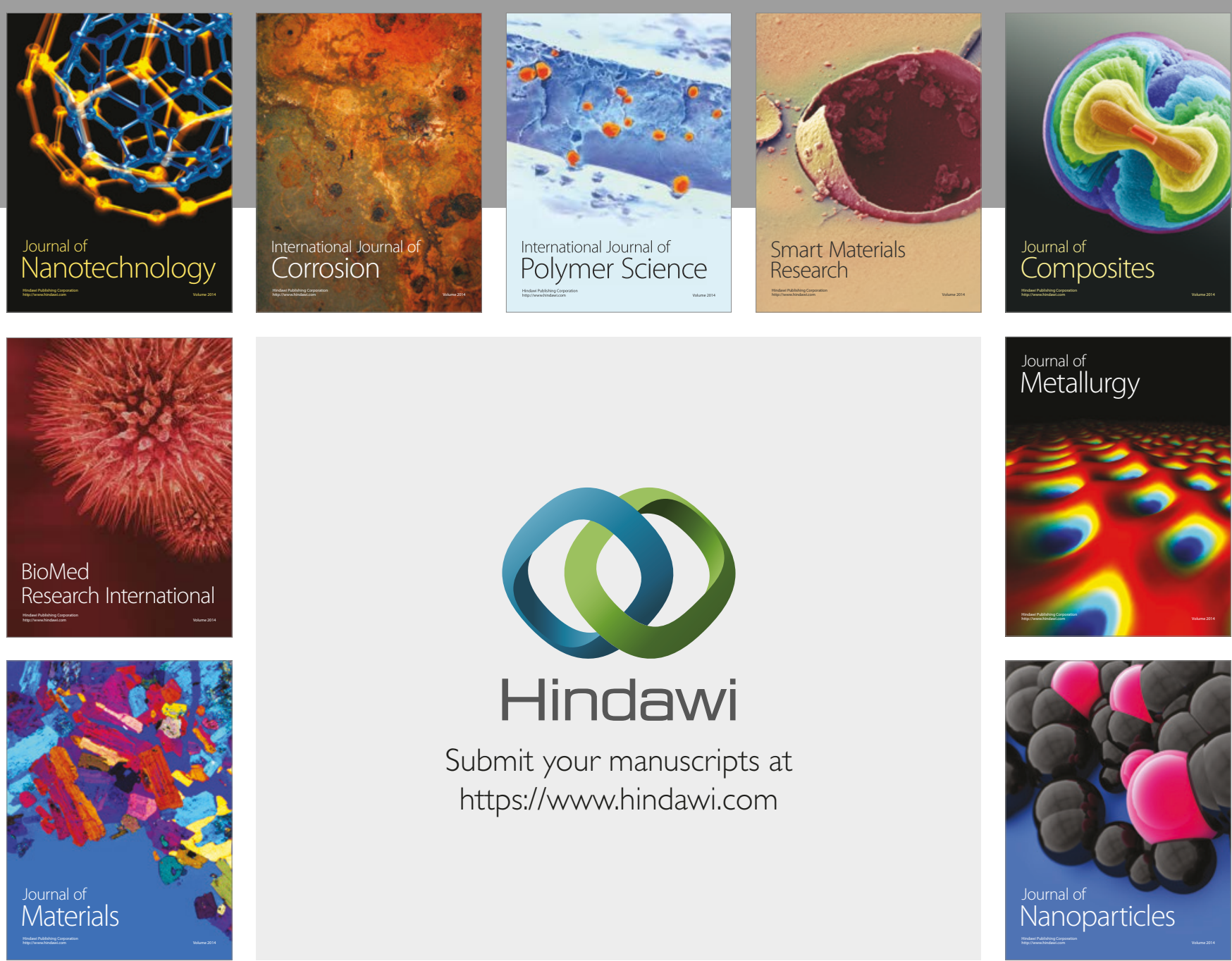

\section{Hindawi}

Submit your manuscripts at

https://www.hindawi.com
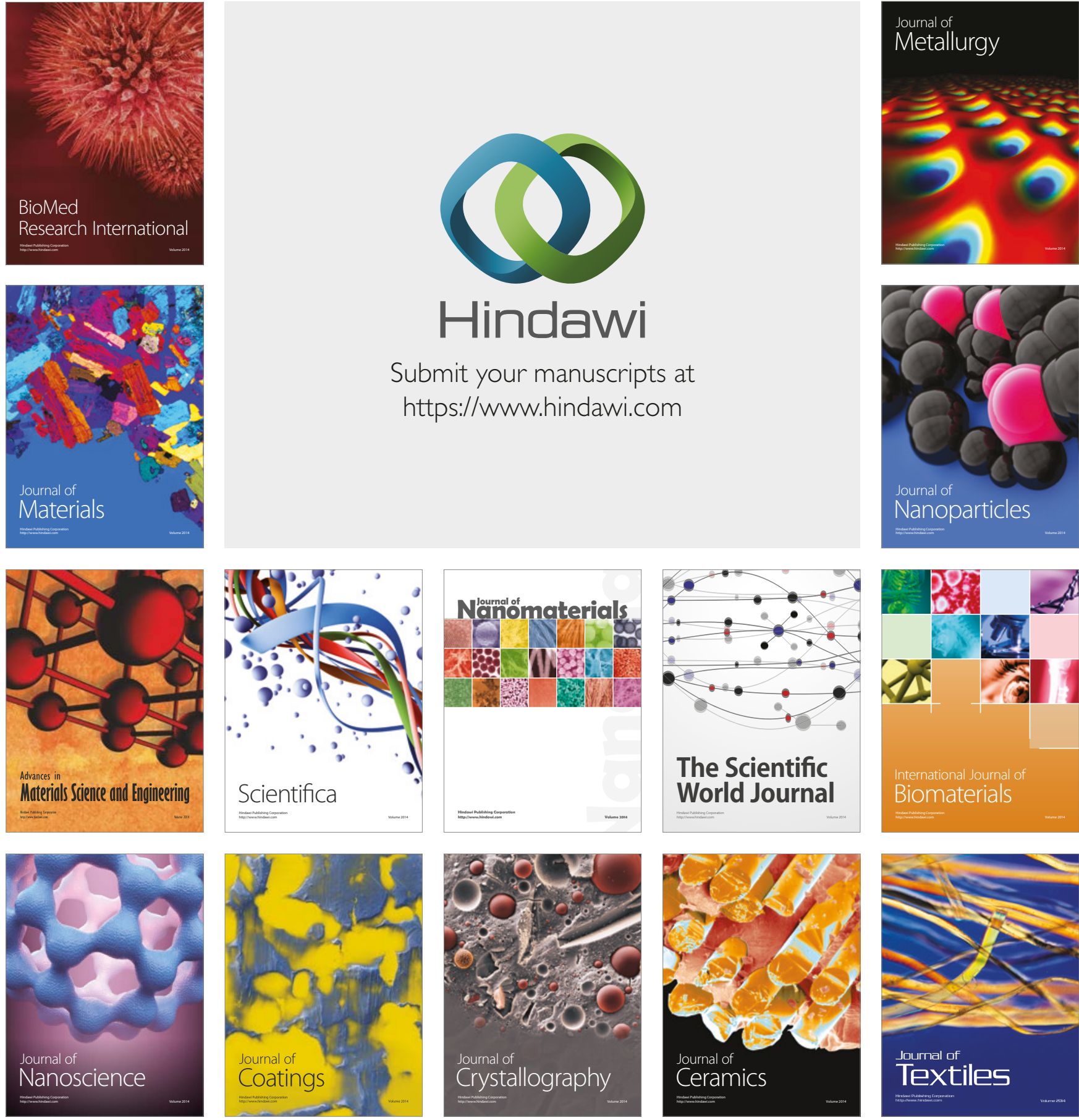

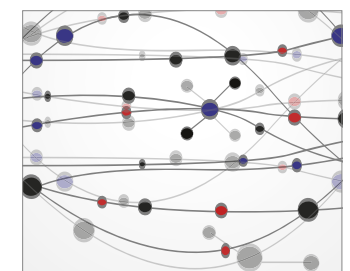

The Scientific World Journal
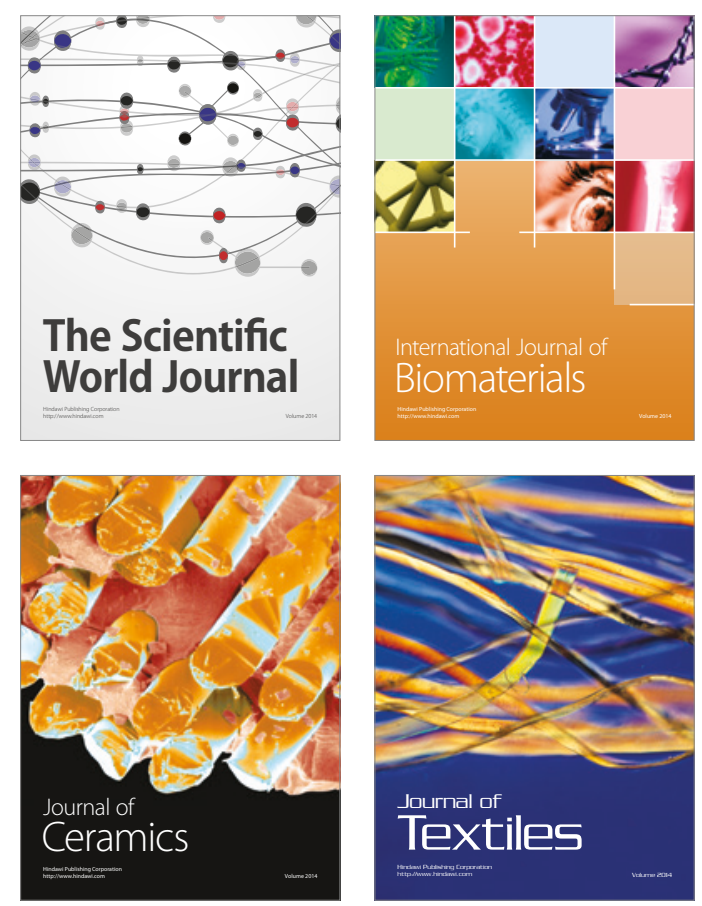